\title{
Judicialização da regulação e perda da qualidade do fornecimento de energia elétrica em áreas periféricas
}

\author{
Maurílio de Abreu Monteiro \\ Universidade Federal do Pará \\ Nirvia Ravena \\ Universidade Federal do Pará \\ Cláudio Luciano da Rocha Conde \\ Agência de Regulação de Serviço Público do Estado do Pará
}

\begin{abstract}
Este estudo analisa os resultados da mudança na estrutura de regulação do serviço público de energia elétrica, implementada, no âmbito da Reforma do Estado, no final dos anos 1990. Foi comparada a qualidade do serviço de distribuição no fornecimento de energia elétrica de duas empresas que atuam no Norte do Brasil, uma pública, outra privada. A última, ao ser penalizada pela agência reguladora, recorreu, sistematicamente, à judicialização dos processos punitivos. Essa estratégia não foi observada na atuação da empresa pública. Tal possibilidade institucional decorre de as agências serem dependentes do Judiciário que opera sob lógica estruturalmente diferente da lógica gerencial. Concluiu-se que a judicialização enseja comportamentos baseados na procrastinação no âmbito do arcabouço regulatório dos serviços públicos, bloqueando a estratégia pública de regulação.
\end{abstract}

Palavras-chave: Reforma do Estado; regulação de serviços; judicialização; qualidade da energia elétrica.

Judicialización de la regulación y la pérdida de calidad del suministro de energía eléctrica en zonas periféricas

Este estudio analiza los resultados de los cambios en la estructura reguladora del servicio público de energía eléctrica, implementado en el ámbito de la Reforma del Estado a finales de 1990. Se comparó a la calidad del servicio de distribución en el suministro de energía eléctrica de dos empresas que operan en el Norte de Brasil, una pública, otra privada. La última, al ser penalizada por la agencia reguladora, recurrió sistemáticamente, a la judicialización de los procesos punitivos. Esta estrategia no se observó en el desempeño de las empresas públicas. Esta posibilidad institucional transcurre de las agencias seren dependientes del Judiciario que opera bajo la lógica estructuralmente diferente de la lógica gerencial. Se concluyó que la judicialización implica en comportamientos basados en la

Artigo recebido em 21 dez. 2011 e aceito em 23 nov. 2012.

Rev. Adm. Pública - Rio de Janeiro 47(2):403-419, mar./abr. 2013 
procrastinación en el ámbito del marco regulatorio de los servicios públicos, bloqueando la estrategia pública de regulación.

Palabras clave: Reforma del Estado; regulación de los servicios; judicialización; calidad de la energía eléctrica.

The judicialization of quality regulation and the loss of electrical power supply to peripheral areas

This study analyzes the results from a structural change in the regulation of the public electricity service implemented as a national reform in the late 1990s. We compared the quality of the electricity supply for two companies, one private and one public, operating in the northern Brazil. The quality indicators for the supplied energy deteriorated for the private company, and once penalized by the regulatory agency, the company systematically judicialized the punitive processes. This strategy was not observed in the actions taken by the public company. The possibility for institutional judicialization occurs because these agencies are dependent on judicial frameworks, which operate within a logic that is structurally different than managerial logic. We concluded that judicialization creates the opportunity for procrastination-based behaviors within the context of the regulatory framework for public services, thereby impeding the public strategy of regulation.

KEY WORDs: State reform; service regulation; judicialization; electric power quality.

\section{Introdução}

Neste artigo, a qualidade do serviço público de distribuição de energia elétrica é abordada a partir da comparação dos resultados da regulação desse serviço e do padrão de atuação de empresas que o prestam, quando lhes são aplicadas punições. Essa comparação visa a uma companhia pública e uma empresa privada. Já a regulação, por sua vez, diz respeito à interação das esferas privada e pública, que, historicamente, envolve tensões entre mercado e Estado, e entre os agentes que operam no interior da arena criada pela ação desses atores (Eisner, Worsham e Rinquist, 2000; Majone, 1989). O processo regulatório resulta da contenda de interesses que se estruturam com base em lógicas coletivas. Os atores organizados buscam ter acesso a nichos do poder estatal e então garantir nessa arena uma ótima relação do ponto de vista custo-benefício (Olson, 1965).

A comparação tem como referência inicial a década de 1990, momento em que, com o empreendimento da Reforma do Estado brasileiro, houve uma mudança institucional nas formas de regulação. Foi criada a Agência Nacional de Energia Elétrica (Aneel) visando à regulação dos serviços de energia elétrica, e a maioria das companhias públicas responsáveis pela exploração do serviço público de distribuição de energia elétrica foi privatizada.

No escopo da Reforma do Estado, em junho de 1998, no estado do Pará, o controle acionário do poder público das Centrais Elétricas do Estado do Pará (Celpa) foi transferido para a iniciativa privada. Diferentemente, no estado de Rondônia, a concessão para explorar serviços públicos de geração, transmissão, distribuição e comercialização de energia elé- 
trica permaneceu sob o controle de uma empresa pública: a Centrais Elétricas de Rondônia S.A. (Ceron).

Como todas essas mudanças que ocorreram no âmbito da Reforma do Estado brasileiro, nos anos 1990, este texto inicialmente aborda o ideário desta e as relações entre os seus fundamentos e as novas bases da regulação dos serviços públicos. Em seguida, discute-se como estratégias de judicialização foram desenvolvidas no interior desse novo padrão de organização do Estado. Por fim, demonstram-se as diferenças, entre a empresa privada e a pública, na adoção de estratégias de judicialização e as implicações de tal padrão em relação à capacidade de atuação das agências de regulação e à qualidade do serviço de fornecimento de energia elétrica.

\section{0 ideário da Reforma do Estado}

A Reforma do Estado no Brasil acompanhou a dinâmica derivada do Consenso de Washington nos países em processo de consolidação de suas democracias (Williamson, 1990). A afirmação do capitalismo e de suas instituições de mercado, após o colapso do socialismo real, foi a tônica desse movimento (Vallinder e Tate, 1995; Santos, 1998, 2001; Carvalho, 2004). Dessa forma, a Reforma do Estado no Brasil e seu vínculo com a judicialização da política marcam um movimento global que confere ao Judiciário nas democracias em processo de consolidação o papel de controle dos demais poderes (Santos, 2002; Oliveira, 2005; Vianna et al., 1999). No Brasil, as mudanças institucionais não foram triviais e simultaneamente impactaram os processos de controle de constitucionalidade realizado pelo Judiciário. Assim, as questões relativas ao peso das instituições nesses processos são apontadas pelo mainstream da ciência política como elementos relevantes (Sweet, 1999; Carvalho, 2007; Vianna, Burgos e Salles, 2007) para a análise proposta por este artigo.

A partir da criação do Ministério da Administração e Reforma do Estado (Mare), em 1995, os rumos da Reforma do Estado brasileiro foram sendo delineados com maior clareza.

O ideário de reforma apoiava a criação do Mare numa modalidade de uso de recursos de poder. Tal ideário partiu da convicção de que "as organizações privadas e as públicas não estatais têm poder apenas sobre os seus funcionários, enquanto que o Estado tem poder para fora dele, detém o 'poder de Estado': o poder de legislar e punir, de tributar e realizar transferências a fundo perdido de recursos" (Bresser-Pereira, 1998:63). Nesta nova modalidade de Estado são erigidas as fundações do Estado social-liberal que associa preceitos democráticos à racionalidade de mercado, tendo como elemento inovador o controle social, o qual garante que essa nova forma de Estado "proteja os direitos sociais ao financiar as organizações públicas não estatais - que defendem direitos ou prestam serviços de educação, saúde, cultura, assistência social — e seja mais eficiente ao introduzir a competição e a flexibilidade da provisão desses serviços" (Bresser-Pereira e Grau, 1999:17).

Essa mudança também focou a potencialização de um comportamento administrativo do tipo gerencial. A transformação da burocracia estatal em administração gerencial seria o 
propósito da mudança. Caiden lembra que se afirmava que: "o governo não pode ser empresa, mas pode tornar-se mais empresarial" (Caiden, 1991:88 apud Clad, 1998:126), isto é, "pode ser mais ágil e flexível diante das gigantescas mudanças ambientais que atingem todas as organizações" (Clad, 1998:126). Todavia, a proposta de alteração nos arranjos institucionais não teve a força argumentativa que garantiria ao processo de Reforma do Estado mais legitimidade. O caminho "discussão - decisão — prática — impacto", como o melhor trajeto para a confecção de novos arranjos institucionais que promoveriam mudanças mais significativas, foi desconsiderado. A ânsia de implementação de mudanças, ideologicamente formuladas, ocupou essa trilha. Em seu lugar, uma interpretação profundamente ideológica da administração pública define a reforma como consequência natural da eterna contenda entre o arcaico e o moderno.

Nos pressupostos da Reforma do Estado, o campo comportamental constitui um dos principais focos da mudança. O desempenho gerencial garantiria o sucesso dessa nova administração. Convergiriam para os resultados todos os esforços e todas as curvas virtuosas da administração gerencial. Nos resultados, concretizar-se-iam o controle dos agentes administrativos e o atendimento ao cidadão (Bresser-Pereira, 1998).

Assim, apenas em circunstâncias pontuais, como a ocorrência de comportamento do tipo rent-seeking, seriam utilizados métodos burocráticos. Em seu lugar, na maioria das vezes, adotou-se uma combinação de estratégias que maximizam a eficiência estatal, tornando-a uma saída para os males oriundos do excesso de procedimentos na burocracia.

No discurso, as instituições administrativas existentes são inadequadas, e é essa a grande constatação que demonstra a necessidade da Reforma. Ironicamente, esta não tem origem em nenhuma sinergia entre a conquista de direitos e a construção de instituições para exercêlos. A Reforma do Estado é elaborada exógena e isoladamente, construindo sua argumentação sobre evidências que se apresentam de forma fluida e não muito consistente para angariar legitimidade. Paralelamente a esse movimento, as instituições políticas mantinham-se, e a judicialização da política começava a ser erigida. Esse tópico será tratado posteriormente, mas é necessário o destaque. Não havia simultaneidade entre a reforma administrativa e a mudança dos padrões de interação entre cidadãos e Estado.

A ideologia e a retórica da ineficiência e da inadequação da administração burocrática latino-americana, presentes nos discursos acerca da necessidade de Reforma do Estado, ficam mais evidentes nos documentos elaborados pelos participantes do Centro Latino-Americano de Administração para o Desenvolvimento (Clad).

Desconsiderando as sutis, mas importantes, diferenças na constituição das instituições políticas dos países latino-americanos, um "tamanho único" ou um prêt-à-porter que se enquadra em todas as realidades e suas variantes resulta como prescrição para a reforma.

A solução para esse contexto institucional, apresentada sem a definição precisa dos procedimentos, quase sempre adota outras culturas institucionais e administrativas como exemplo. Assim, os policy makers latino-americanos, pós-reformas, surgiriam em um contexto democrático ainda não consolidado, no qual o tempo para que seja internalizada a mudança é preterido em função da urgência das Reformas. A não associação dos novos marcos regulató- 
rios originados pela Reforma do Estado às formas de operacionalização da justiça deixou aos judiciários regionais um legado que resultou na possibilidade da judicialização da regulação.

\section{Mudanças institucionais e sobreposição de racionalidades}

Mudanças institucionais, como apontam Feeny (1993) e Levi (1990), devem estar acopladas aos arcabouços constitucionais para que tenham efetividade, pois é necessário que, do ponto de vista da aplicabilidade, os novos arranjos sejam acolhidos no interior do ordenamento jurídico que rege os princípios constitucionais.

A literatura institucionalista recente considera necessário, nas mudanças institucionais que envolvem mudanças constitucionais, o consenso acerca das mudanças e, de certa forma, há uma recomendação para que ambas, a institucional e a constitucional, sejam efetivadas com base na legitimação do caráter de autoridade e da delegação que os governos detêm nos sistemas democráticos.

Para Oakerson (1993), não há como transformar as instituições sem amparar as alterações no bojo de um marco constitucional legitimado. Essa legitimação, provavelmente, deve ser atingida em meio ao confronto de várias expectativas quanto à mudança. Entre aderir e opor-se a esta, entrecruzam-se vários interesses. Uma vez que as constituições são arranjos compostos por um conjunto de regras desenhadas para facilitar comportamentos recíprocos em relação a um conjunto de problemas e oportunidades comuns (Oakerson, 1993:149), a cada mudança, essas regras, quando aceitas e determinadas consensualmente, devem reforçar-se. Qualquer alteração que se busque implementar nos arranjos institucionais existentes não deve fugir aos limites dos marcos constitucionais preestabelecidos e fruto de consensos anteriores à mudança pretendida, pois a transgressão pode pôr em risco tanto a implantação quanto a consolidação do novo desenho a ser adotado (Feeny, 1993; March e Olsen, 1989).

Nesse ponto reside a grande força adquirida pela crescente judicialização da regulação, imprimindo descompasso entre a racionalidade gerencial da regulação de serviços universais, como a energia elétrica, e a racionalidade que guia a atuação de outras instituições. Adicionam-se, aos problemas oriundos da sobreposição das racionalidades ministerial e de agências, problemas de delegação. Para Epstein e O'Halloran (1999) e Melo (2001), a delegação imputa aos processos grandes perdas de agenciamento, elevando custos de transação e dificultando processos de reciprocidade contratual, aumentando as assimetrias de poder inerentes a outros com essas características. A marcha da mudança e a sobreposição de racionalidades fragilizaram as instituições que iriam abrigar as novas modalidades de contratos surgidos no interior de modelos gerenciais de regulação, e o tempo em que se efetivou a mudança dos modelos regulatórios explica em parte essa fragilidade (Castor, 2001; Prats i Català, 1998).

Implementaram-se mudanças institucionais com base no suposto equivocado de que, na América Latina, a composição da administração pública era uma desviante do tipo ideal e que os governos latino-americanos poderiam queimar a etapa necessária para a constituição da sequência administração patrimonialista, administração burocrática e administração geren- 
cial (Brasil, 1995a, 1995b). O modelo gerencial não precisava, portanto, do pleno desenvolvimento da administração burocrática para ser implementado. Bastava que novas instituições fossem criadas e que o controle de resultados, e não de procedimentos, se instalasse como verdadeiro instrumento da mudança da cultura administrativa nas organizações.

Esse diagnóstico, particularmente expresso nos escritos do Plano Diretor da Reforma do Aparelho do Estado (PDRF) (Brasil, 1995b), permitiu uma série de ações em busca da implementação de uma cultura gerencial em curto espaço de tempo. A performance mensurada quando do controle dos resultados seria o "atalho" para a conquista da nova cultura administrativa. Nesse sentido, uma nova inadequação apresentava-se: a adesão à Reforma por setores da burocracia e o oportunismo dos atores alocados no mercado. Porém, a interação entre essa nova administração e as estruturas do Judiciário não foi dimensionada. Mais que isso: a judicialização da política que já operava não se constituiu em um alerta para que os adeptos da Reforma previssem problemas futuros com a judicialização da regulação.

\section{Judicialização da política e da regulação: diferenças e similaridades do mesmo jogo}

A judicialização da política é abordada, na literatura recente, como um processo em que o Judiciário é evocado para controlar constitucionalmente os atos do Executivo e do Legislativo (Vallinder, 1995; Vallinder e Tate, 1995). Esse processo seria o desdobramento da complexificação dos sistemas democráticos que, mediante controle de constitucionalidade, acionam mecanismos de revisão judicial e aportam ao sistema de checks and balances mais um instrumento de controle. As discussões sobre o papel do Judiciário nas democracias atuais transitam das análises do ativismo deste à judicialização da política (Vianna, Burgos e Salles, 2007; Koerner, 2007; Santos, 2007; Maciel, 2011), sendo o olhar para a judicialização da regulação mais recente (Koerner, 2004; Santos e Rodríguez-Garavito, 2005; Ginsburg, 2009; Rose-Ackerman e Lindseth, 2010; Rodríguez-Garavito, 2011). Em todas, o fenômeno da globalização aparece como definidor do novo papel assumido pelo Judiciário.

Neste contexto, para o Brasil, Arantes (1996), Pinheiro (1998) e Pinheiro, Sadek e Lamounier (2000) introduzem as questões relativas ao comportamento do Judiciário e suas consequências na dinâmica econômica, geralmente criando cenários de incertezas e de ineficiência. O processo de judicialização no Brasil é descrito densamente por Vianna e colaboradores (1999) e por Arantes (1997) e, mais recentemente, por Carvalho (2007), Engelmann (2007), Koerner (2004), Santos (2007) e Maciel (2011).

Arantes (1997) demonstra que o ativismo do Judiciário teria criado no Brasil um híbrido institucional, ao combinar lógicas de natureza de controle diferenciadas, como a constitucionalidade de caráter central e o direito difuso. Para ele, esse híbrido traz consequências nefastas para a governabilidade e para a governança. É nesse ponto que a judicialização da política assume importância na discussão sobre a judicialização da regulação, pois ambas decorrem de uma mesma lógica presente nos jogos de interação entre Estado e sociedade, mas 
produzem efeitos diferenciados, porque as regras se originaram em ambientes institucionais distintos.

Tem sido constante nas abordagens atuais sobre o papel do Judiciário na regulação a interpretação de que o ativismo judicial atua nos momentos decisórios e de formulação e impacta também no processo de tomada de decisão ex post (Taylor, 2007; Carvalho, 2007; Silva e Costa Júnior, 2009; Ginsburg, 2009; Rose-Ackerman e Lindseth, 2010; D'Alberti, 2010). Trabalhos voltados à ação do Judiciário no Brasil na definição de políticas públicas (Taylor, 2007), sociais (Maciel, 2011) e setoriais (Silva e Costa Júnior, 2009), na posição de juristas em carreiras de estado (Engelmann, 2012), apontam cada vez mais a interface do campo jurídico e político.

Os dispositivos constitucionais de interferência no jogo político (politics) e de consecução de políticas públicas (policy) são bastante expandidos na Carta brasileira. Couto e Arantes (2006) arguem que, na Carta de 1988, os contendores procuraram, por meio dos dispositivos constitucionais, extrapolar a ação da Carta na vida política ordinária. A Constituição de 1988, com sua possibilidade de constrangimento da ação dos atores na politics, tem o poder de interferir e até mesmo de definir o desenho das policies.

Embora as questões acerca do ativismo do Judiciário e suas consequências sobre as políticas públicas tenham sido tratadas recentemente (Oliveira, 2005; Taylor, 2007; Carvalho, 2007; Maciel, 2011), é importante destacar que a matriz institucional, para a qual a regulação de serviços como a energia elétrica foi constituída, não obedece apenas ao marco constitucional, mas origina-se de uma tentativa de mudança institucional já relatada detalhadamente nas seções anteriores em que se descreve a Reforma do Estado. Isso significa que a falta de consolidação dos desenhos regulatórios preconizados por esta última teve um impacto decisivo no desenrolar de processos de produção de políticas públicas. Elas são, então, resultado da conjunção do híbrido institucional e das trajetórias dependentes criadas pela Carta de 1988.

O caso apresentado neste trabalho permite inferir que a degradação da qualidade na prestação de serviços de fornecimento de energia elétrica por empresas privadas advém da inoperância regulatória resultante dos ciclos de judicialização da regulação provocados pela empresa, que encontra oportunidades no desenho regulatório e no marco constitucional para apresentar-se como ente que demanda tratamento ligado ao direito privado.

Emprestamos de Oliveira (2005) o conceito aplicado de judicialização da política, baseado na dinâmica que a autora define como ciclo de judicialização, para utilizá-lo de forma similar ao processo de judicialização da regulação. O processo assim se desenrola:

primeiramente no acionamento do Judiciário através do ajuizamento de processos — ou politização da justiça; em segundo lugar, no julgamento do pedido de liminar (quando houver); e, por fim, no julgamento do mérito da ação 1, que enseja a judicialização da política propriamente dita. Este é o que chamarei aqui de ciclo da judicialização. (Oliveira, 2005:560)

A intencionalidade dessa ação é conhecida na literatura econômica sobre regulação. Grupos de interesse demandam regulação para mitigar as falhas de mercado. Stigler (1971) e 
Peltzman (1989) demonstram que reguladores buscam alocar de forma ótima a demanda de consumidores e a oferta dos produtores. Para os autores, os reguladores alocam benefícios de forma ótima para maximizar a utilidade política da regulação. Ou seja, consumidores e produtores, como grupos de interesse que têm peso na escolha política dos governantes, devem ter perdas e ganhos relativos no jogo regulatório. Mas, sob a judicialização, o que ocorre é a procrastinação intencional.

Enquanto comportamento de atores econômicos, a procrastinação no mundo econômico, segundo Akerlof (1991), é o exemplo mais simples de situação em que consistentemente ocorrem erros de julgamento, devido à saliência de alguns custos e benefícios. Na abordagem de Akerlof, a procrastinação é um comportamento desviante da racionalidade que impera nas decisões econômicas.

\section{Padrões de atuação de concessionários ante a punição regulatória}

No caso da prestação do serviço de fornecimento de energia elétrica, a possibilidade de que modelos regulatórios com baixo grau de efetividade promovam a procrastinação é alta. Isso ocorre não somente porque os atores julgam de forma equivocada, mas sobretudo porque as regras induzem à procrastinação. No momento em que a regulação fica subordinada à lógica da judicialização, sua operacionalização leva a um julgamento que não está submetido à expertise técnica que orienta uma racionalidade decisória no momento do julgamento no interior do ciclo de judicialização da regulação. Ao contrário, o híbrido institucional traz à cena o ato de postergar como estratégia de diminuição de custos para o cumprimento da regulação. É o que se observa ao se comparar o padrão de atuação de duas empresas.

A Celpa e a Ceron detêm a concessão para a distribuição de energia elétrica junto à Aneel nos estados do Pará e de Rondônia, respectivamente. Essas concessões foram instituídas mediante contratos. O primeiro estabeleceu o vencimento da concessão em 2028 e o segundo em 2015.

Como já se indicou, em julho de 1998, a Celpa foi privatizada e seu controle acionário passou a ser exercido pelo Grupo Rede Energia S.A., que detém 61,37\% de suas ações totais. Já a Ceron mantém-se pública, sendo controlada pela empresa Centrais Elétricas Brasileiras S.A. (Eletrobrás), detentora de $99,96 \%$ do capital social.

Cabe à Aneel regular os serviços de energia elétrica prestados. Em Rondônia, ela assumiu diretamente essa prerrogativa; no Pará, delegou a atribuição à agência estadual: Agência de Regulação de Serviço Público do Estado do Pará (Arcon).

A avaliação da qualidade do fornecimento de energia elétrica envolve, sob a ótica da regulamentação, dois aspectos: continuidade do fornecimento e conformidade dos níveis de tensão. A continuidade do fornecimento de energia elétrica é definida pelos indicadores coletivos e individuais de atendimento, com forma de cálculo, apuração e metas definidas pela Aneel. Os indicadores de continuidade de conjunto são: Duração Equivalente de Interrupção 
por Unidade Consumidora (DEC) e Frequência Equivalente de Interrupção por Unidade Consumidora (FEC).

O primeiro é a duração, medida em horas, do tempo durante o qual cada consumidor de determinado conjunto ficou interrompido, em média. Da mesma forma, o FEC representa a quantidade de vezes em que, em média, cada consumidor do conjunto ficou interrompido (Aneel, 2000). Em 2010, no estado do Pará, esses indicadores foram calculados tendo por base 188 conjuntos de unidades consumidoras que abarcavam 1,7 milhão de consumidores; em Rondônia, no mesmo ano, foram 56 conjuntos que compreendiam 346 mil consumidores (Aneel, 2011).

Os autores desse artigo, com base nos dados da Aneel (2011), agregaram os indicadores de conjunto de unidades consumidoras para a totalidade da área geográfica atendida por concessionária, produzindo, assim, indicadores para as empresas. Pode-se assim comparar a evolução do DEC (horas de interrupção) e do FEC (quantidade de vezes de interrupção) médios da Celpa e da Ceron, desde 2001 (gráfico 1). A comparação é efetuada a partir do ano mencionado, porque os indicadores anteriores utilizaram critérios diferentes para a apuração do DEC e do FEC (Aneel, 2000).

\section{Gráfico 1}

Evolução do desempenho de indicadores de continuidade no fornecimento de energia pela Celpa e pela Ceron, no período de 2001 a 2010

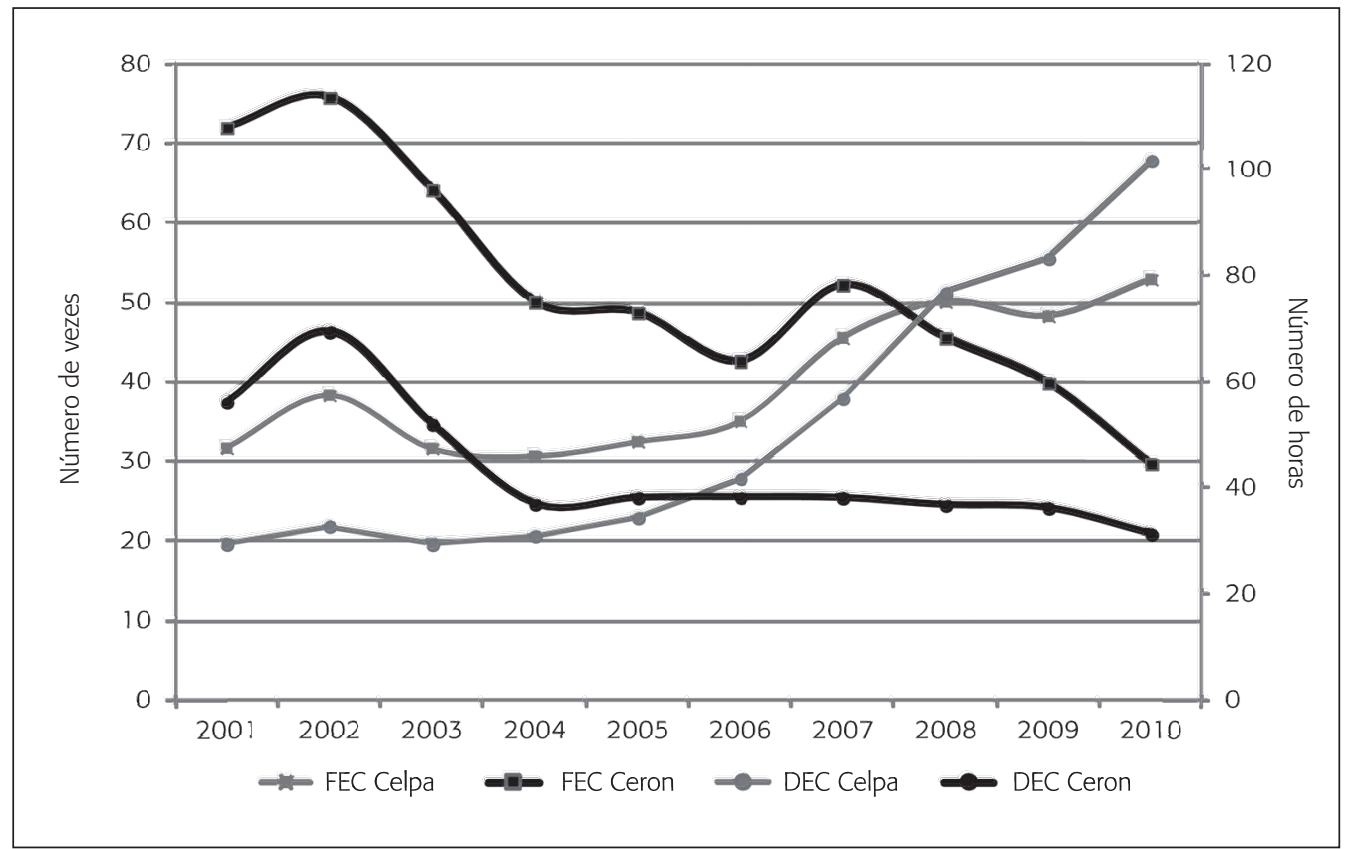

Fonte: Cálculo e elaboração dos autores tendo por base Aneel (2011). 
Os indicadores de continuidade apresentam comportamento inverso: os consumidores atendidos pela Ceron convivem com a tendência de melhora no DEC e no FEC; já os consumidores atendidos pela Celpa, com a tendência de crescente degradação desses indicadores de qualidade. Essa tendência de comportamento dos indicadores, tomados no âmbito do Estado, também é reproduzida em âmbito menos agregado, não se tratando, portanto, de um fenômeno restrito a algumas regiões dos estados analisados (gráfico 2).

A forma de apuração e de definição das metas de cada conjunto de consumidores é estabelecida pela Aneel. As metas mensais, trimestrais e anuais são, em geral, decrescentes ano a ano, para que as empresas responsáveis pela distribuição de energia elétrica melhorem progressivamente a qualidade do fornecimento em sua área de concessão, até que elas se aproximem dos padrões internacionais de atendimento.

Gráfico 2

Evolução do percentual de conjuntos de consumidores nos quais houve violação das metas de continuidade de fornecimento de energia nos estados do Pará e de Rondônia, no período de 2001 a 2010

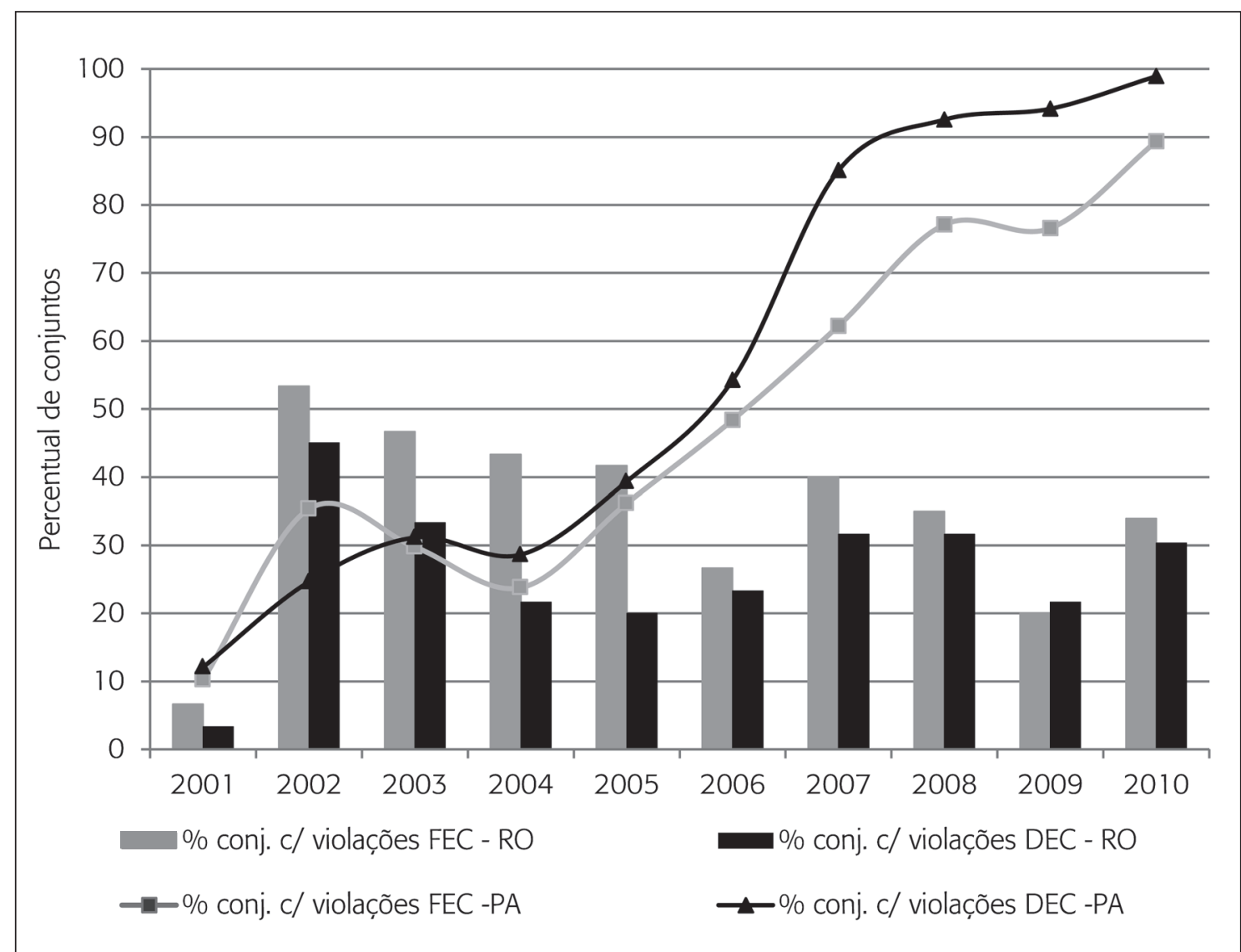

Fonte: Elaboração dos autores tendo por base Aneel (2011). 
Ao se inferir o número de conjuntos de consumidores que apresentaram violações de metas, ou seja, o número daquelas regiões (conjuntos) nas quais as metas para o DEC e o FEC não foram cumpridas, constata-se a tendência de piora dos indicadores para o estado do Pará e de melhora para os diversos conjuntos de consumidores de Rondônia. No caso do Pará, trata-se de indistinta e crescente degradação da qualidade da energia fornecida, atingindo a quase totalidade dos conjuntos de consumidores, desde aqueles localizados na capital desse estado até os localizados nas porções que dela mais se distanciam (gráfico 2).

\section{A judicialização e o bloqueio da regulação pública}

As agências reguladoras, para procurar garantir a qualidade de fornecimento de energia elétrica aos consumidores pela Celpa e pela Ceron, recorreram a ações administrativas previstas juntamente com a criação das agências de regulação no âmbito da Reforma do Estado brasileiro. Utilizaram, desse modo, instrumentos de regulação, como audiências públicas, fiscalizações, multas, termos de ajuste de conduta, certificados de descumprimento, entre outros.

A Arcon, por delegação da Aneel, realizou fiscalizações dos serviços de fornecimento de energia elétrica no Pará. As fiscalizações realizadas no período de 2000 a 2008, em função de irregularidades constatadas, entre as quais a violação dos padrões de DEC e de FEC, ensejaram a expedição pela agência reguladora de 33 autos de infração, dos quais resultou a aplicação de multas que totalizaram $\mathrm{R} \$ 55$ milhões, como punição à concessionária Celpa pelas irregularidades constatadas.

Em Rondônia, onde a fiscalização é efetivada diretamente pela Aneel, entre 2003 e 2010, houve pelo menos 13 autos de infração e um certificado de descumprimento, como resultado das fiscalizações e como punição à concessionária Ceron pelas irregularidades constatadas. As autuações resultaram em multas cujo montante atingiu R \$ 46,4 milhões. Desse valor, 56\% são decorrentes dos descumprimentos das metas de DEC e de FEC pela Ceron.

A Celpa recorreu administrativamente de todas as multas e, como não tinha sucesso nesse âmbito, recorreu judicialmente a todas as multas aplicadas. Tal padrão de atuação ante a ação do órgão regulador fez com que migrassem para a esfera judiciária os processos que deveriam encerrar-se nas arenas da regulação. Em função dessa estratégia, do valor total das multas, somente foi pago R \$ 0,24 milhão, correspondente a 0,44\% do valor total. Isso, efetivamente, minou a capacidade desse instrumento de regulação pública de alterar padrões de conduta da concessionária, o que é claramente refletido nos indicadores.

A Ceron também recorreu administrativamente das multas que lhe foram impostas pela Aneel. Todavia, vencida essa etapa, não recorria ao Judiciário, estabelecia Termos de Ajustes de Conduta (Tac) com a agência reguladora. Manteve, assim, os processos nas arenas da regulação, atuando nos limites do modelo regulatório, com postura cooperativa. A empresa apresenta em balanços anuais previsão, na sua dotação orçamentária, de recursos para o cumprimento das penalidades regulatórias (Ceron, 2010:131). 
Fica evidente que os mecanismos de regulação pública não garantiram, no caso do Pará, a melhoria nas condições de fornecimento de energia elétrica. Eles também não têm sido capazes de provocar tensões que conduzam a concessionária a realizar investimentos para reverter a tendência de queda na qualidade dos serviços. Essa realidade pode ser observada pela evolução da potência instalada em transformadores de distribuição na rede urbana. Em 2001, a potência nominal instalada em transformadores de distribuição correspondia a 948 MWA; a despeito do crescimento da demanda e do número de consumidores, a potência instalada em transformadores para atender a rede urbana manteve-se quase inalterada: em 2008, ela equivalia à potência nominal de 1.071 MWA.

A despeito do baixo volume de investimento realizado pela concessionária e da tendência na queda da qualidade de serviços, as agências de regulação não conseguiram vedar operações de empréstimo da Celpa para outras empresas do grupo. Tanto que, em dezembro de 2009, esta já era credora, de empresas relacionadas, em mais de R\$ 622 milhões (tabela 1).

\section{Tabela 1}

Saldo da Celpa com empresas relacionadas, em dezembro de 2009

\begin{tabular}{|lc|}
\hline Empresa relacionada & Valor $(\mathrm{R} \$ \times 1000)$ \\
\hline Rede Energia S.A. & 7.926 \\
QMRA Participações S.A. & 20.430 \\
Rede Energia S.A. & 112.144 \\
QMRA Participações S.A. & 386.524 \\
Rede Power do Brasil S.A. & 95.285 \\
TOTAL & 622.309 \\
\hline
\end{tabular}

Fonte: Celpa (2009).

Por conseguinte, no ambiente de regulação do serviço de fornecimento de energia elétrica, há a possibilidade tanto de posturas não cooperativas, ou mesmo oportunistas, quanto de atuações cooperativas. A comparação entre a Ceron e a Celpa, em relação aos indicadores de qualidade do fornecimento de energia e ao padrão de atuação ante a imputação de sanções regulatórias pelas agências reguladoras, revelou que a segunda empresa utiliza brechas na legislação para realizar atos que, embora sejam legais, apontam para um comportamento de procrastinação na melhoria dos padrões de fornecimento de energia que findam por se mostrar contrários aos interesses da concessão, na medida em que a concessionária, ao ser autuada pela regulação pública, busca na judicialização os meios para manter padrões de atendimento inferiores aos determinados na regulação. Evidencia-se, assim, um dos limites da estratégia de regulação dos serviços desenhados no âmbito da Reforma do Estado, levada a efeito nos anos 1990: a judicialização da regulação. 


\section{Considerações finais}

A judicialização da regulação, em grande medida, pode ser explicada pela implementação de desenhos regulatórios em dissonância com a história institucional dos países que adotaram o modelo de agências para regular serviços e produtos (Ginsburg, 2009; Rose-Ackerman e Lindseth, 2010; Rodríguez-Garavito, 2011) e também com o papel que o Judiciário passou a desempenhar depois da globalização (Santos e Rodríguez-Garavito, 2005). No Brasil, para as questões ligadas ao fornecimento de energia, evidencia-se que, no seu nascedouro, o modelo de regulação já prenunciava um anacronismo institucional que atropelou a dimensão simbólica, historicamente construída nas instituições. O Judiciário adentrou o campo político, transformando o controle constitucional em instrumento vital na condução dos conflitos entre Estado e sociedade (Vianna, Burgos e Salles, 2007).

Nas políticas públicas setoriais, como a de regulação de serviços de fornecimento de energia elétrica, a judicialização segue o caminho apontado por Oliveira (2005), o que finda transformando o processo de regulação num Quasimodo institucional, dado o efeito da judicialização da regulação. Conforme apontado neste estudo, a procrastinação na melhoria do atendimento, para que o serviço de fornecimento de energia elétrica da Celpa obedecesse às determinantes dadas pela regulação do setor, encontra no Judiciário as janelas de oportunidades criadas pela delegação da regulação em instâncias concorrentes. Leia-se: agências reguladoras e tribunais.

Nas esferas de delegação da regulação do serviço de fornecimento de energia elétrica, o movimento de incompatibilidade assume proporção de escala. Mesmo tendo a presumida autonomia, do ponto de vista da operacionalização da regulação, as agências regionais veemse presas a arcabouços do Judiciário, quando intentam buscar eficiência e eficácia na provisão dos serviços. Assim, na gênese da atual estrutura de regulação de serviços, os custos de transação da adequação do quadro constitucional, ao serem evitados, introduziram os lock-in na trajetória da mudança. Do ponto de vista da interação entre os novos modelos de regulação, a Celpa procrastina, pois as oportunidades para esse comportamento estão dadas pela judicialização. Assim, o não pagamento de multas por meio do início do ciclo de judicialização da regulação é uma atitude diante do que é disponibilizado como regra do jogo regulatório.

Ao acionar a burocracia judiciária, atores privados, como a Celpa, encontram oportunidades para evitar o fairness esperado nas relações contratuais (Williamson, 2005). Um simulacro da tragédia dos comuns. Posterga-se, assim, a tão propalada melhoria dos serviços públicos advinda da Reforma administrativa. Enclausuram-se a sociedade e as gerações futuras na esfera de um direito que, ao não servir aos cidadãos, certamente serve às corporações. Manieta-se o desenvolvimento regional, não só pela interferência das novas estratégias dos atores com maiores recursos de poder na esfera econômica, mas também pela impossibilidade de que a energia elétrica sirva a propósitos mais dignificantes do que somente a eficiência energética. 


\section{Referências}

AGÊNCIA NACIONAL DE ENERGIA ELÉTRICA. Aneel. Indicadores de continuidade (informações técnicas/distribuição de energia elétrica/qualidade dos serviços). Disponível em: <www.aneel.gov. br/aplicacoes/Indicadores_de_Qualidade/norte.cfm>. Acesso em: 27 set. 2011.

AGÊNCIA NACIONAL DE ENERGIA ELÉTRICA. Aneel. Resolução no 024, de 27 de janeiro de 2000. Estabelece as disposições relativas à continuidade da distribuição de energia elétrica às unidades consumidoras. Diário Oficial da União, Brasília, DF, 28 jan. 2000. Seção 1, p. 24-26. Disponível em: <www.aneel.gov.br/cedoc/res2000024.pdf.>. Acesso em: 27 set. 2011.

AKERLOF, George A. Procrastination and obedience. The American Economic Review, v. 81, n. 2, p. 1-19, may 1991.

ARANTES, Rogério B. A crise do Judiciário no Brasil. Revista Trevisan, São Paulo, n. 104, p. 18-27, 1996.

ARANTES, Rogério B. Judiciário e política no Brasil. São Paulo: Sumaré, 1997.

BRASIL. Ministério da Administração e da Reforma do Estado. Mare. Cadernos Mare da Reforma do Estado. Brasília, v. 12, 1995a.

BRASIL. Presidência da República. Câmara da Reforma do Estado. Plano Diretor da Reforma do Aparelho do Estado (PDRF). Brasília: Mare, 1995b.

BRESSER-PEREIRA, Luiz C. A Reforma do estado dos anos 90: lógica e mecanismos de controle. Lua Nova, n. 45, p. 49-95, 1998.

BRESSER-PEREIRA, Luiz C.; GRAU, Nuria C. (Org.). O público não estatal na reforma do estado. Rio de Janeiro: Fundação Getulio Vargas, 1999.

CAIDEN, Gerald E. Administrative reform comes of age. Nova York; Berlin: Walter de Gruyter, 1991.

CARVALHO, Ernani R. Em busca da judicialização da política no Brasil: apontamentos para uma nova abordagem. Revista de Sociologia e Política, n. 23, p. 127-139, nov. 2004.

CARVALHO, Ernani R. Revisão judicial e judicialização da política no direito ocidental: aspectos relevantes de sua gênese e desenvolvimento. Revista de Sociologia e Política, n. 28, p. 161-179, jun. 2007.

CASTOR, Belmiro V. J. Os contornos do estado e da burocracia no Brasil. In: CASTOR, Belmiro V. J. et al. Burocracia e reforma do estado. São Paulo: Fundação Konrad Adenauer, 2001. p. 9-28. (Cadernos Adenauer II, n. 3).

CENTRAIS ELÉTRICAS DE RONDÔNIA. Ceron. Demonstrações contábeis: 2010. Disponível em:<www. Ceron.com.br/PDF/Demonstracoes\%20Contabeis\%202010.pdf>. Acesso em: 25 set. 2011.

CENTRAIS ELÉTRICAS DO PARÁ S/A. Celpa. Relatório da Administração: 2009. Disponível em: <www.redenergia.com/concessionarias/Celpa/residenciais.aspx>. Acesso em: 7 abr. 2010. 
CENTRO LATINO-AMERICANO DE ADMINISTRAÇÃO PARA O DESENVOLVIMENTO. Clad. Uma nova gestão pública para a América Latina. Caracas: Clad, 1998.

COUTO, Cláudio G.; ARANTES, Rogério B. Constituição, governo e democracia no Brasil. Revista Brasileira de Ciências Sociais, São Paulo, v. 21, n. 61, p. 41-62, 2006.

D'ALBERTI, Marco. Administrative law and the public regulation of markets in a global age. In: ROSE-ACKERMANN, Susan; LINDSETH, Peter L. (Ed.). Comparative administrative law. Northampton: Edward Elgar Publishing, 2010.

EISNER, Allen M.; WORSHAM, Jeffrey; RINGQUIST, Evan J. Contemporary regulatory policy. Boulder, CO: Lynne Rienner Publishers, 2000.

ENGELMANN, Fabiano. Globalização e poder de estado: circulação internacional de elites e hierarquias do campo jurídico brasileiro. Dados - Revista de Ciências Sociais, Rio de Janeiro, v. 55, n. 2, p. 487-516, 2012.

ENGELMANN, Fabiano. Internacionalização e ativismo judicial: causas políticas e causas jurídicas nas décadas de 1990 e 2000. Revista Contexto Internacional, v. 29, n. 1, p. 39-62, jan./jun. 2007.

EPSTEIN, David; O'HALLORAN, Sharyn. Delegating powers: a transaction cost politics approach to policy making under separate powers. Cambridge: University Cambridge Press, 1999.

FEENY, David. The Demand and supply of institutional arrangements. In: OSTROM, Vincent; FEENY, David; PITCH, Hartmut (Ed.). Rethinking institutional analysis and development: issues, alternatives, and choices. San Francisco, CA: ICS Press, 1993. p. 159-209.

GINSBURG, Tom. Judicialization of administrative governance: causes, consequences and limits. In: GINSBURG, Tom; CHEN, Albert H. Y. (Ed.). Administrative law and governance in Asia: comparative perspectives. Routledge University Press, 2009.

KOERNER, Andrei. Direito e regulação: uma apresentação do debate teórico no Réseau Européen Droit et Société. BIB — Revista Brasileira de Informação Bibliográfica em Ciências Sociais, n. 58, p. 79-130, 2004.

KOERNER, Andrei. Instituições, decisão judicial e análise do pensamento jurídico: o debate norteamericano. BIB — Revista Brasileira de Informação Bibliográfica em Ciências Sociais, n. 63, p. 63-86, 2007.

LEVI, Margaret. A logic of institutional change. In: COOK, Karen S.; LEVI, Margaret (Ed.). The limits of rationality. Chicago: University of Chicago Press, 1990. p. 402-418.

MACIEL, Débora A. Ação coletiva, mobilização do direito e instituições políticas: o caso da campanha da Lei Maria da Penha. Revista Brasileira de Ciências Sociais, São Paulo, v. 26, n. 77, p. 97-111, out. 2011.

MAJONE, Giandomenico. Evidence argument and persuasion in policy process. Yale: Yale University Press, 1989.

MARCH, James G.; OLSEN, Johan P. Rediscovering institutions: the organizational basis of politics. Nova York: The Free Press, 1989. 
MELO, Marcus A. A política da ação regulatória: responsabilização, credibilidade e delegação. Revista Brasileira de Ciências Sociais, São Paulo, v. 16, n. 46, p. 55-68, jun. 2001.

OAKERSON, Ronald J. Reciprocity: a bottom-up view of political development. In: OSTROM, Vincent; FEENY, David; PICHT, Harmut (Ed.). Rethinking institutional analysis and development: issues, alternatives, and choices. San Francisco, CA: ICS Press, 1993. p. 141-158.

OLIVEIRA, Vanessa E. de. Judiciário e privatizações no Brasil: existe uma judicialização da política? Dados — Revista de Ciências Sociais, Rio de Janeiro, v. 48, n. 3, p. 559-587, 2005.

OLSON, Mancur. The logic of collective action. Harvard: University Press, 1965.

PELTZMAN, Sam. The economic theory of regulation after a decade of deregulation. Brooking Papers: Microeconomics, v. 89, p. 1-42, 1989.

PINHEIRO, Armando C. A reforma do Judiciário: uma análise econômica. In: SEMINÁRIO INTERNACIONAL "SOCIEDADE E REFORMA DO ESTADO”, 1998, São Paulo. Anais... São Paulo, 1998. p. 226-228.

PINHEIRO, Armando C.; SADEK, Maria T. A.; LAMOUNIER, Bolívar (Org). Judiciário e economia no Brasil. São Paulo: Sumaré, 2000.

PRATS I CATALÀ, Joan. Administración pública y desarrollo en América Latina: un enfoque neoinstitucionalista. Revista del Clad Reforma y Democracia, Caracas, n. 11, p. 7-48, jun. 1998.

RODRÍGUEZ-GARAVITO, César. Toward a sociology of the global rule of law field: neoliberalism, neoconstitutionalism, and the contest over judicial reform in Latin America. In: DEZALAY, Yves; GARTH, Brylant G. (Ed.). Lawyers and the rule of law in an era of globalization, 2011. p. 164-165.

ROSE-ACKERMAN, Susan; LINDSETH, Peter L. Comparative administrative law: an introduction. In: ROSE-ACKERMAN, Susan; LINDSETH, Peter L. (Ed.). Comparative administrative law. Northampton: Edward Elgar Publishing, 2010. p. 1-20.

SANTOS, Boaventura de S. A reinvenção solidária e participativa do Estado. Coimbra: Faculdade de Economia da Universidade de Coimbra, Centro de Estudos Sociais, 1998.

SANTOS, Boaventura de S. Derecho y democracia: la reforma global de la justicia. In: SANTOS, Boaventura de S.; VILLEGAS, Mauricio G. (Org.). El caleidoscopio de las justicias em Colombia. Bogotá: Ediciones Uniandes, Siglo del hombre, 2001.

SANTOS, Boaventura de S. Direito e democracia: a reforma global da justiça. In: PUREZA, José M.; FERREIRA, António C. (Org.). A teia global: movimentos sociais e instituições. Porto: Edições afrontamento, 2002.

SANTOS, Boaventura de S.; RODRÍGUEZ-GARAVITO, César. Law, politics, and the subaltern in Counter-hegemonic globalization. In: SANTOS, Boaventura de S.; RODRÍGUEZ-GARAVITO, César. (Org.). Law and globalization from below: towards a cosmopolitan legality. Cambridge: Cambridge University Press, 2005. p. 1-26. 
SANTOS, Cecília M. Ativismo jurídico transnacional e o estado: reflexões sobre casos apresentados contra o Brasil na Comissão Interamericana de Direitos Humanos. SUR - Revista Internacional de Direitos Humanos, v. 4, n. 7, p. 27-57, 2007.

SILVA, Rafael S. e; COSTA JÚNIOR, Álvaro P. S. Como medir o impacto das decisões do Judiciário sobre a implementação da política regulatória? Cadernos de Finanças Públicas, Brasília, n. 9, p. 103-135, dez. 2009.

STIGLER, George J. The theory of economic regulation. The Bell Journal of Economics and Management Science, v. 2, n. 1, p. 3-21, 1971.

SWEET, Alec S. Judicialization and the construction of governance. Comparative Political Studies, v. 32, n. 2, p. 147-184, apr. 1999. Disponível em: < http://works.bepress.com/alec_stone_sweet/2>. Acesso em: 20 set. 2011.

TAYLOR, Matthew M. O Judiciário e as políticas públicas no Brasil. Dados - Revista de Ciências Sociais, v. 50, n. 2, p. 229-257, 2007.

VALLINDER, Torbjörn. When the courts go maching in. In: VALLINDER, Torbjörn; TATE, C. Neal (Ed.). The global expansion of judicial power. Nova York: New York University, 1995. p. 13-26.

VALLINDER, Torbjörn; TATE, C. Neal. The global expansion of judicial power. Nova York: New York University, 1995.

VIANNA, Luiz W. et al. A judicialização da política e das relações sociais no Brasil. Rio de Janeiro: Revan, 1999.

VIANNA, Luiz W.; BURGOS, Marcelo B.; SALLES, Paula M. Dezessete anos de judicialização da política. Tempo Social: Revista de Sociologia da USP, São Paulo, v. 19, n. 2, nov. 2007.

WILLIAMSON, John. What Washington means by policy reform. In: WILLIAMSON, John (Ed.). Latin American adjustment: how much has happened? Washington: Institute for International Economics, 1990. p. 5-20.

WILLIAMSON, Oliver. Por que direito, economia e organizações? In: ZYLBERSZTAJN, Décio; SZTAJN, Rachel (Org.). Direito \& economia: análise econômica do direito e das organizações. Tradução de Décio Zylbersztajn. Rio de Janeiro: Elsevier, 2005. p. 16-59.

Maurílio de Abreu Monteiro é professor e pesquisador do Núcleo de Altos Estudos Amazônicos (Naea) da Universidade Federal do Pará (UFPA). E-mail: maurilio_naea@ufpa.br.

Nirvia Ravena é professora e pesquisadora do Núcleo de Altos Estudos Amazônicos (Naea) e do Programa de Pós-Graduação em Ciência Política (PPGCP) da Universidade Federal do Pará (UFPA). E-mail: niravena@uol.com.br.

Cláudio Luciano da Rocha Conde é técnico da Agência de Regulação de Serviço Público do Estado do Pará (Arcon). E-mail: conde@interconect.com.br. 
